\title{
Environmental Consciousness, Sustainability, and the Character of Philosophy of Education
}

\author{
Michael Bonnett ${ }^{1}$ (D)
}

(C) The Author(s) 2016. This article is published with open access at Springerlink.com

\begin{abstract}
This paper argues that education itself, properly understood, is intimately concerned with an individual's being in the world, and therefore is ineluctably environmental. This is guaranteed by the ecstatic nature of consciousness. Furthermore, it is argued that a central dimension of this environment with which ecstatic human consciousness is engaged, is that of nature understood as the 'self-arising'. Nature, so conceived, is essentially other and is epistemologically mysterious, possessing its own normativity, agency, and intrinsic value. As such, engagement with nature presents opportunities for consciousness quintessentially to go beyond itself, to be inspired and refreshed, and to receive non-anthropogenic standards in the form of intimations of what is fitting and what is not. It will be argued that these are fundamental to the orientation of human being, providing primordial intimations of the nature of reality and truth. Given their centrality to the idea of a person's becoming educated, the elucidation of these and the issues to which they give rise must be central to the philosophy of education and in this sense it becomes deeply ecological.
\end{abstract}

Keywords Environmental consciousness - Sustainability · Nature · Human being · Scientism $\cdot$ Metaphysics of mastery $\cdot$ Philosophy of education

\section{Introduction}

Philosophy of education can be understood as engaged in the analysis and elucidation of the nature of education: the ideas that inform it and the practices that are taken concretely to constitute it. This broad characterization can rapidly be unpacked in terms of a wide range of more specific and intimately interrelated considerations, such as the character of

Michael Bonnett

mrb25@cam.ac.uk

1 Universiy of Cambridge, Cambridge, UK 
teaching, learning, the curriculum and the pupil-teacher relationship - and also, the institutions such as schools and universities in which they occur. In turn, these considerations can lead to a number of underlying issues, for example concerning the nature of truth, knowledge and understanding; the nature and relevance of moral, social/political, aesthetic, and other values. And, perhaps, most fundamental of all: the nature of human subjectivity and personhood, and their relationship to the greater world that they inhabit, and of which they are a part. If something like this portrayal is accepted, it places the question of what it is to be human - that is to say, the character of its existence and potentiality - at the heart of philosophy of education. This has held true for many of the most influential philosophies of education, including those of Plato, Rousseau, Dewey, R. S. Peters, and the philosophers of Bildung.

It seems to me that it is on this topic of the nature and potentiality of human existence that concerns elaborated in the discourses of sustainability and environmental education have some important things to say. Indeed, they can be interpreted as requiring a significant re-orientation of the philosophy of education as largely it currently presents itself. I will begin to open up this issue by attempting to elucidate and defend what in recent times has become a heavily contested idea: that of an authentic human essence.

There is a long history of conceiving the self, not as some separate autonomous entityas has been attributed to some forms of liberalism—but as essentially relational. ${ }^{1}$ This has sometimes resulted in subjectivity becoming understood largely as merely the creation and on-going reflection of external influences, as illustrated in varying degree through, say, ideas of 'subjectivation' through the performative activities of others ${ }^{2}$ or the subject's coming into presence only through the recognition of others. ${ }^{3}$ Here, the possibility of an authentic human essence is in danger of becoming dissipated across an interminable range of external agencies. ${ }^{4}$ Yet, through its attempt to define what it is to be human, the idea of an authentic human essence can be portrayed as placing arbitrary restrictions upon human potentiality that in turn involve a colonisation of humanity by the views of the elites who decide the criteria. ${ }^{5}$

However, there are alternative ways of acknowledging the relational dimension to human being and that emphasize the involvement with an environment without jettisoning the idea of a self that possesses some sort of internal integrity and whose characterizing aspects can be articulated to some degree. One such notion of authentic human essence derives from a formulation of the idea of consciousness derived from medieval schoolmen and re-introduced into modern philosophy by Franz Brentano in the latter half of the nineteenth century: the intentionality thesis. It will be argued that here, with some modifications, can be discerned a view of human being that holds the possibility of developing a notion of human essence in which the way in which we are ineluctably environmental is linked to a primordial idea of sustainability. I will argue that this has the potential to reorientate our understanding of philosophy of education.

In his Psychology from an Empirical Standpoint Franz Brentano employed the idea of intentionality as a way of distinguishing consciousness from the merely physical. ${ }^{6} \mathrm{He}$

\footnotetext{
1 See, for example, Seigel (2005, Ch. 1).

2 Espoused by Butler (1997).

3 Biesta (2006).

4 Bonnett (2009a).

5 A gross example of this would be the Enlightenment elevation of European bourgeois reason as universal arbiter of thinking - aptly dubbed by Robert Solomon as the 'transcendental pretence' (Solomon 1980).

6 Brentano (1995).
} 
interpreted intentionality as 'relationship to a content, the tendency towards an object' that is immanent, i.e. contained within consciousness. This idea of consciousness as essentially directed upon an object, being 'minded', subsequently was taken up by Edmund Husserl ${ }^{7}$ and seminally modified by his argument that the things to which consciousness is directed-its intentional objects-are not contained within itself, but are transcendent. For example, when we desire something such as a new coat, we do not desire something that is already within consciousness, say an image or an idea, but an actual coat whose existence lies beyond any individual consciousness. Furthermore, as Martin Heidegger makes clear in his rejection of Husserl's developing transcendental idealism, we experience these transcendent objects as always already existing in a world that they share with us. ${ }^{8}$ Such 'worldliness' is fundamental to their intelligibility. Human consciousness is ecstatic in this sense of existing in a constant (and complex) motion of standing out towards things beyond itself in the world. In this sense it is ineluctably worldly-and hence, we can say, environmental. And its internal integrity can be conceived as a constantly evolving genealogy of intentionality in which past acts condition, but far from determine, future acts. ${ }^{9,10}$

For the purpose of illustrating how this internal relationship between consciousness and its environment connects with ecological concerns that can affect how we think about the idea of an authentic human essence, and in turn, how we should understand philosophy of education, I will develop two central aspects: (1) the primordial character of human ecstasis as a kind of sustaining; (2) the significance of the experience of nature.

\section{Human Being as Sustainability}

In other work, ${ }^{11}$ I have argued that there is a pregnant sense in which sustainability lies at the heart of human consciousness, and that it is intimately entwined with a founding notion of truth. The argument goes as follows.

If it is proper to characterize human consciousness as intentional in the sense outlined above, it follows that the greater the range and integrity of the intentional objects in which it participates, the greater will be the richness of its own life. And because these objects are transcendent and therefore not to be conceived as exclusively the product of its own projections, primordially its stance will need to be one of receptiveness to what engages it. Although he makes no explicit reference to any intentionality thesis, something very like it can be interpreted as being present in Bertrand Russell's introductory text The Problems of Philosophy. ${ }^{12}$ In the concluding chapter 'The Value of Philosophy', he suggests that true knowledge is a union of the Self with the not-Self. It is important to note that in the case of philosophy this union is not to be understood as generating a body of definitely ascertainable knowledge. Rather, Russell holds that: 'The value of philosophy is, in fact, to be

\footnotetext{
7 Husserl (2001).

8 Heidegger (1972).

9 Bonnett (1978).

${ }^{10}$ It should be made clear here that two senses of 'intentional' come into play: first, a direct pre-predicative engagement that is to be distinguished from (2) having an intention in the further deliberative sense of, say, working on a problem or deciding a course of action. Each feeds into the other. In what follows the reference is mainly to the pre-predicative sense of intention, although it is part of the broader picture that such prepredicative engagement plays into intention in the more deliberative sense.

11 Bonnett (2004).

12 Russell (1959).
} 
sought largely in its very uncertainty' and the consequent speculation that 'suggests many possibilities which enlarge our thoughts and free them from the tyranny of custom'. ${ }^{13}$ In this way even the smallest and most familiar things in life can become strange and enlarged in their significance. This leads Russell to make a seminal point that reveals a key implication of the intentionality thesis when considered from an educational point of view:

Apart from its utility in showing unsuspected possibilities, philosophy has a value perhaps its chief value - through the greatness of the objects that it contemplates, and the freedom from narrow and personal aims resulting from this contemplation. ${ }^{14}$

He goes on to make it clear that such enlargement of Self does not occur through study that 'wishes in advance that its objects should have this or that character, but adapts the Self to the characters which it finds in its objects... In contemplation... we start from the not-Self, and through its greatness the boundaries of Self are enlarged; through the infinity of the universe the mind which contemplates it achieves some share in infinity'. ${ }^{15,16}$

In this fundamental sense of consciousness being attentive to what its intentional objects present, it is involved in a sustaining of things - a letting them be as the things that they are. This is the basis of world-formation. And here, too, resides an originary sense of truth: an apprehension of things as they are in their own being. It should be noted that this is not to posit some objective reality entirely independent of consciousness; rather it is to speak of the reality in relationship to which primordially consciousness consists or lives, and, by the same token, the reality that occurs through consciousness, as the place where it can show up. As it were, subject and object are poles of the relationship that is consciousness. The poles can be distinguished, but arise only as aspects of this original relationship that constitutes consciousness and that at base is one of mutual anticipation. Elsewhere, ${ }^{17} \mathrm{I}$ have argued that anticipation in its varied forms pervades all that we do and experience: for example, for the walker that the earth will bear her up or for the reader that the text has meaning, and while often deeply implicit, also it is deeply enlivening and can be quite explicit—as with the anticipation of meeting a friend after a long absence, or setting off on a cross-country ramble on a fine spring morning.

Furthermore, such anticipation is not simply our projection onto an inert world. It occurs in the context of our participation in places, and a place and the things that populate and constitute it can be experienced as awaiting us and as claiming us through the invitations and prompts that they offer. Perhaps we look into the kitchen and see the dirty dishes awaiting our attention, the shade of a tree beckons us on a hot day. We can experience the history or ambience of a particular place as deeply affecting our sense of who we are and what we are doing. This is true whether it is our home with its familiar utensils that

\footnotetext{
13 Ibid, 91.

14 Ibid, 91.

15 Ibid, 92.

${ }^{16}$ It is true that in his desire to make philosophic contemplation impersonal and dispassionate-as free as possible from human hopes and fears, customary beliefs and traditional prejudices-Russell claims that the free intellect 'will value more the abstract and universal knowledge into which the accidents of private history do not enter, than the knowledge brought by the senses, and dependent, as such knowledge must be, upon an exclusive and personal point of view and a body whose sense-organs distort as much as they reveal' (p. 93). This discounting of the role of affect and the body in sense-making clearly goes against some central themes of this paper. But his cabined notion of understanding does not vitiate the point that from within the constraints of a very different viewpoint emerges the essential underlying insight that there is an intimate relationship between enlargement of self and openness to the otherness of things.

17 Bonnett (2009b).
} 
anticipate and invite our activity there, the solitude of an upland stream, or the endless lines of white war graves of the Somme that silently await our coming and remembrance. The significances that we experience in these examples are not merely subjective additions to something more primal or real, rather they constitute the world of sense in which we liveand from which all else is abstraction and fabrication.

It is important to make clear that this sense of reciprocal anticipation in our experience of the world emanates not only from the clearly artefactual, but also from the quintessentially non-artefactual: nature. The spider's web anticipates the stray fly; after a hard winter the swelling buds standing out on dark stems anticipate warmer and longer days. Reaching for a ripe fruit, it can be experienced as awaiting our grasp; the nearby robin awaits alert for the disturbance that will expose hidden grubs as I take my fork to the soil. We exist through our participation in this interplay of anticipation. Without it, indeed, we would enter ontological freefall, for there is an important sense in which we ourselves inhere in the world through a meshing of our anticipations with those experienced in the places in which we live and in which essentially we find ourselves. In the case of 'natural places', this can range from an unreflective picking of an inviting apple, to a more general attunement to the myriad signs of what is nascent on a spring day that shapes our own anticipations and thus locates us in the play of the seasons. Ultimately there is nothing purely objective or passive about a place-_domestic' or 'natural'; it only appears so when we have lost touch with its, and our own, genius - as when, under the influence of scientism, we can be persuaded that to recognize its transcendent inviting otherness is to indulge a frothy fiction.

Because it illustrates these points in a powerful way, and also because it leads to issues that lie at the heart of ideas of ecologizing philosophy of education, I will now turn to an elucidation of our experience of nature.

\section{The Significance of Nature}

The key feature of our experience of nature qua nature- that is to say the experience that lies at the kernel of our concept of nature-is its independence of our authorship and will. In this sense things in nature are quintessentially self-arising, ${ }^{18}$ befalling us in their individuality and particularity as non-artefactual, essentially other. However, two caveats need to be entered here.

First, this is far from saying that in all our encounters with nature its self-arising character is what is most prominent. On occasion it may be heavily veiled or subverted. Indeed, it may be that increasingly and for the most part we come to see things in nature in purely instrumental or economic terms, paying little or no attention to their particularity and otherness. The point being made is that insofar as we do still construe something as a part of nature, the idea of it as self-arising is implicit, and furthermore that this understanding of nature both is deeply embedded in our form of sensibility and is an essential element of it (of which more anon).

Second, of course, we can affect nature in all sorts of ways, but in all our interactions with it there remains something that is 'other', always beyond us and experienced as occurring from out of itself-And this, notwithstanding the fact that our linguistic articulations of nature occur through concepts that have been socially produced. Perhaps, on my cross country ramble a freshening breeze sets the boughs of some great tree dancing.

${ }^{18}$ Bonnett (2004), op. cit. 
Clearly, this is understood and articulated through the relevant socially produced concepts, but that the boughs moved in this way and at this moment is perfectly independent of these concepts.

Having recognized this element of autonomy in nature, it is important to note that there is a complex relationship between the play of human purposes and the disclosure of the otherness of nature. While often our contact with an intelligible world is modulated by the purposes and practices that we pursue, equally, aspects of that world can announce themselves 'uninvited'. Perhaps we suddenly experience a marked change of temperature or a powerful odour, or our attention is commanded by the sudden apprehension of something neither foreseen nor imagined-such as a clap of thunder emanating from brooding clouds that have crept up on us unawares. Furthermore, our artefacts are frequently both shaped by our awareness of aspects of nature with which we have to contend, such as the weather, and can reveal facets of that nature such as the way that a glass prism can display the colours concealed within white light.

And, of course, this intimate interplay and reciprocal conditioning of human purposes and artefacts with the appearing of nature in its otherness occurs within - and constantly extends-our overarching form of sensibility. This latter evolved precisely in response to the presence of otherness in its myriad changing forms, and historically whose most powerful and pervasive example is that of self-arising nature that both has shaped our senses and whose presence as an independent reality is implicit in the logic of our senses and the languages used in relation to them, such as those of perception and description. Hence, the nature that we experience is human-related in that human consciousness provides the place and occasion for its appearances, but ultimately not simply human-authored. In experience, the living presence of natural things is something we behold rather than construct, and we take such things to have their own 'lives' and interactions, regardless of whether we witness or speculate about them. ${ }^{19}$

This experience of the living presence of natural things brings me to another important aspect of self-arising nature. Scientific ecology has drawn attention to the ways in which things in nature are biophysically interdependent, individuals being causally sustained as integral members of local ecosystems, which in turn are nested in overarching regional or global systems. However, from the phenomenological perspective, there is another important sense in which things in nature exist always in relationship: not now as scientifically defined objects or constructs, but in their very occurring-in their being. In other work $^{20}$ I have argued that the character of their living presence-the things that they are in our sensory experience of them-occurs through the mutually sustaining relationships that constitute place-making. To return to the example of the upland stream: the glistening flow of water eddying around tumbled polished rocks, the mysterious movement of a reed at the margin where the water is quiet, the momentary silver glint of a darting fish, the fragrances borne on the fresh breeze that blows at this place and that disturbs the pendant branches of a stunted willow that overhangs the stream at this spot, its fissured bark displaying and withholding strange shapes as sunlight and cloud shadow pass over it: Here the living presence of each is sustained through its participation in a creative interplay with all. This mutual interplay constitutes the place in which they are encountered. It is sustained by them and sustaining of them. Removed-perhaps the fish to an aquarium, the stone to a

${ }^{19}$ I have defended the idea of nature as a 'primordial reality' against postmodern/poststructuralist critiques that all understandings of nature as an underlying reality are the products of narratives that in various ways are arbitrary or even 'optional' in the early chapters of Retrieving Nature (Bonnett 2004).

20 Bonnett (2012). 
rock collection-their being is transformed, reduced to that of curio. In such uprooting, their existence arises through their participation in a new imposed interplay that is in part both parasitic on what they once were and at the same time subverts key aspects of their self-arising nature, their ability to befall us as natural.

If we enter a natural place and participate in the vibrancy of its being-the placemaking that is occurring - our own embodied being is enlivened and refreshed, our senses resonating with pure engagement, united with what they receive. For a while our ecstatic nature is fulfilled. Herein lies a central aspect of the importance of self-arising nature: where it is prominent we can experience an ecstasis that can be inspirational by re-opening a space for possibilities of otherness and mystery that far outrun any preconceptions and knowingness with which habitually we equip and insulate ourselves. Things in nature are quintessentially other in the sense of having their own histories and futures, profiles and countenances, many of which we will never see and that can never be fully anticipated. The attentive walker in natural space is subject to frequent surprise as things encountered offer invitations to participate in their being in unique and never wholly predictable ways. They possess aspects that always lie beyond us, withdrawn, yet to be revealed, no matter how developed our scientific understanding becomes. And sometimes partly because of this, as when the living presence of the rock or willow tree are codified in some database pro forma of objective defining properties. Participation in the spontaneity and innate epistemological mystery of self-arising nature opens us to truth in its most primordial form: in Heideggerian vein, the coming into presence of things themselves and their withdrawing. In such a relationship we can come to feel the elemental powers that are at play: for example, those of birth and death, lightening and darkening, sound and silence, motion and stillness, and so forth. ${ }^{21}$ These all embody significances both for human as well as nonhuman nature, as when perhaps a silence is experienced as uncanny and laden with foreboding, or the dawn light resonates with hope.

And there is another important point to be made here. Although they are profoundly other, things in nature communicate something of their own integrity such that we can have a sense of what would count as their fulfilment. In this sense they are normative and possess intrinsic value. Negatively, our awareness of this can be evoked if perhaps, returning to the upland stream, we were to find the bloated corpses of fish borne on foam topped waters smelling of industrial waste. More positively, in experiencing the myriad interplays, harmonies and contrasts, subtle adaptions and accommodations, we might be struck by a sense of rightness emanating from the stream during our first encounter. Things presence in such a way that how they are communicates that this is how they ought to be 22 Here we become acquainted with a form of rightness that is in some sense 'pre-moral': more a matter of an emplaced sensing of what belongs and what is fitting than anything that could be articulated in a set of abstract moral principles or specific prescriptions. But nonetheless, this is an acquaintanceship that can be refined and deepened through an attentive and intimate living alongside things that, for example, has found expression (in very different ways) in the lives of indigenous peoples and in Romantic poetry. ${ }^{23}$ Entry into these can help to (re-)attune us to the presence of normative intimations, respect for which conditions but does not determine moral conduct. Rather such intimations are a pre-

\footnotetext{
21 Bonnett (2015a).

22 Bonnett (2012), op. cit.

23 See, for example, Garrard (1998).
} 
condition of a properly informed ethical response. ${ }^{24}$ And And here, again, we receive indications of truth, of a reality that is true to itself; vulnerable to the effects of overweening human ambition, yet potentially powerful in orientating human being for those sensitive to the silent messages it gives off. ${ }^{25}$

Clearly, there is a sense in which such a claim contravenes that well established dictum in moral philosophy, emanating from Hume, that an 'ought' cannot be derived from an 'is' on the grounds that when an empirical fact is stated it is always possible to question whether it possesses the moral value attributed to it. Taken in loose combination with the the so-called 'naturalistic fallacy' propounded by G. E. Moore, this has sometimes resulted in a radical separation of fact and value, the latter becoming perceived as a mere human projection on some underlying empirical reality. ${ }^{26}$ But from the phenomenological point of view this position has things the wrong way round. Our direct experience of things in nature is not normally that of neutral objects to which value is then added: we experience them as already having value in some respect-they are present to us with their value, which, as Max Scheler once put it, can be experienced as 'streaming off' them. At this level, the position is really an example of a proto-scientism. It deconstructs concrete experience and by a process of abstraction produces a theoretically neutral object and a separate value component. This is not to say that elements of the approach have no relevance in the moral sphere. When it comes to deciding how to act in a particular situation-e.g. whether to preserve or destroy some aspect of nature - the inherent value of one thing alone often cannot determine this; its value needs to be weighed against the values of other things involved, including human-wellbeing. In this sense 'is' does not imply 'ought', but it is a mistake to deploy this as an argument against the idea of intrinsic moral value as it has been taken to do, for in fact it assumes some prior apprehension of intrinsic values.

To be sure, none of this is to deny that we need to be alert to occasions where the normativity claimed to be experienced in 'nature' and what is taken to be 'natural' is recruited to authenticate, for example, dubious conceptions and power relationships such as those associated with gender. ${ }^{27}$ But such misappropriation should not persuade us simply to suspend or disparage, in any wholesale way, experiences of value and normative measures in nature that both constitute a sense of unity with nature and can inform and ground us in significant ways. While, no doubt, there are occasions when moral values have been read into nature to suit current prejudices, phenomenologically this imposition of an agenda is a far cry from the genuine receptivity to otherness that this paper advocates.

Bringing this section to a close, from the position being developed in this paper, a central point that arises in the course of this discussion of nature as the self-arising is that something of the fundamental character of human being becomes foregrounded. Relating to the quintessential otherness of nature in its manifold facets is central to human existence and involves a non-anthropocentric receptivity to things themselves with their innate value.

${ }^{24}$ Bonnett (2012), op. cit. For an illustration of normative intimations arising from nature see, for example, Holmes Rolston III's account of the refusal of rangers in Yosemite National Park to cut a drive-through tunnel through another sequoia after the fall of the famous Wawona tree in the storms of 1968-69. They refused on the grounds that to do so would be an indignity to a majestic sequoia, and that it perverted the trees. Rolston III (1999, p. 120).

25 See, for example, Skulason (2015), for further discussion of this.

26 Moore did not take this route, espousing instead the idea of intrinsic values as 'non-natural properties' that reside in the thing itself and are discerned by the intellect.

27 See, for example, Haraway (1991). 
In sum, at the heart of authentic human essence is the holding sway of truth conceived as an attitude of loving allowance. In this sense it is essentially sustaining and sustained. But in our everyday busy-ness this mutuality with nature is largely effaced by other powerful motives that have come to dominate in our late-modern time.

\section{Nature's Enemies: Scientism and the Metaphysics of Mastery}

By scientism, I refer to the phenomenon of presuming that classical experimental science has a privileged access to the nature of reality; that somehow its methods, findings and constructions reveal what is 'really' real and that therefore it can assume the mantle of arbiter for thinking in general. Clearly, this is to be distinguished from science as a field of research; scientism is a set of presumptions about the significance and application of the assumptions, methodologies and findings of this field of research in our daily lives.

With regard to the natural world-which is here my central concern-it arises, for example, in claims that what in everyday experience we take to be solid objects are to be understood as, say, 'really' bits of space traversed by speeding particles; what we experience as their colour or sound is 'really' movement of a particular wavelength. When it appears to us that a beaver selects a site to build its lodge, protects this site from river surges by quiet pools resulting from felling nearby trees, gnawing them to manageable size and towing them to narrow parts of the river to construct dams, what is 'really' occurring is the working out of blind mechanical processes. The vocabulary of the former everyday account is to be regarded fundamentally as a quaint piece of anthropomorphism.

Elsewhere, ${ }^{28}$ I have questioned this presumption that somehow such scientific accounts are 'truer', more objective in the sense of providing a more authentic depiction of the world-one that properly reflects how it really is. Why privilege blind mechanical depictions of the natural world over those that speak of purpose and agency? Does the natural historian, when implying agency by speaking of a predator hunting its prey, necessarily mis-describe what she sees, or indulge a way of speaking that is merely figurative? Why be tempted to posit as fundamental a world of, say, colourless, blindly hurrying particles when human experience of the natural world is so much richer than this and cannot be adequately articulated through its vocabulary?

I will return to this issue shortly. For the moment I make the point that while the former conception might be quite acceptable within the discipline of science with its particular project towards the world and where its limitations as well as its strengths are recognized, given the richness of experience and depths of intelligibility that it denies, such reductionism looks highly arbitrary when it gets generalised, as with scientism.

Let me now return to the question as to why we can find ourselves condoning scientism. I believe that the answer lies in what I have termed the 'metaphysics of mastery' ${ }^{29}$ I use this epithet to refer to the ways in which Western culture increasingly frames issues in terms that are deeply human-centred and manipulative. While much is still hybrid in this respect, here grows an underlying presumption that everything is to be understood in terms of how it can be brought to serve the human will alone: the purposes that humans give to themselves, increasingly detached from any sensibility of any other source of value, and in

\footnotetext{
28 Bonnett (2013).

${ }^{29}$ In what follows there are clear resonances with, for example, some aspects of Heidegger's analysis of the essence of modern technology (Heidegger 1977). and Plumwood's characterisation of masculine rationality (Plumwood 1995).
} 
which ultimately the desire for mastery comes to reign supreme and everything must be brought to order in its service. Here we have, as it were, the burgeoning of a will that looks only to itself: a kind of hyper-anthropocentrism that now supersedes the fully human and seeks to dominate it, as it would all else. Under its aegis, all values become instrumental and the world, including the natural world, becomes a resource - the purer, the better. The all-consuming goal is that of utility: to have everything to hand with minimum inconvenience and maximum efficiency from the point of view of our self-defined comfort and self-given projects. Anything resistant to this requirement presents itself as being in need of re-engineering or replacement. While this motive is far from new, its increasing dominance and purity has been spurred by - and is expressed in - the growth of technological power. This has led, for the moment, to the throwing off of the old constraints of religion and nature and expresses itself in the burgeoning of consumerism and the choice of alternative virtual realities in which to live and that reflect an increasingly disdainful attitude towards the given.

In the present context this raises the important issue of what such a wilful attitude does to our relationship with nature. The anthropologist Gregory Bateson notes how when faced with a changing variable we tend to focus on modifying our environment rather than ourselves. ${ }^{30}$ This is entirely consistent with the metaphysics of mastery, as are the ever increasingly ambitious aspirations to manage what at one time would have been accepted more or less as natural givens, ranging from, say, our anatomy to the oceans and the climate. Of course, some of these aspirations might be entirely appropriate if, rather awkwardly, simply they expressed a humble acknowledgement of human responsibility for the consequences of its actions upon the natural world and a determination to modify such actions so as to restore to nature its own integrity. But for the most part they do not. They continue to express an overweening desire to order all according to human will-an aggressive anthropocentrism. And it seems plausible to argue that it is precisely this hubris towards the natural world that has led to our current environmental situation.

To begin with, there is the problem that even when matters are set up in scientific terms, the complexity of natural systems and the magnitude of their temporal and spatial scales means that our current knowledge is far from commensurate with such grandiose ambitions. But more fundamental than this, viewing everything in nature as a resource prevents things from showing up as they are themselves. The lack of a felt sense of nature's integrity and normativity itself results in a very partial perception and understanding of the world in which we are embedded, vitiating decision-making and leading inevitably to deleterious consequences. The well documented history of unintended outcomes of human interventions in nature bears witness to this. ${ }^{31}$ And the continued decimation of natural populations and habitats, such as those associated with deforestation and the industrial fishing methods that destroy the sea floor, demonstrate how even when deleterious consequences are known narrow short term interests prevail. Looking at this phenomenon from a different perspective-and taking one stark illustration-how could reducing the North American buffalo population from an estimated 60 million to less than 500 in a period of a few decades ever have come to be regarded as a right thing to do? Only if nature is regarded simply as a disposable resource, possessing no inherent intrinsic value, could such slaughter present itself as a legitimate candidate for deliberate action.

Today, perhaps the most pervasive expression of an underlying attitude of masteryputting nature under the yoke-is exhibited in the strength and character of the consumerist

\footnotetext{
30 Bateson (2000).

31 Such as Carson (1962).
} 
economic motives that dominate Western society and increasingly are becoming globalized. The commodification of all (for example as 'natural capital', 'human capital') is a clear expression of the motive of mastery. Typically it operates by externalising collateral effects that lie outside the chain of 'most efficient' production, unless, that is, these are impressed upon it by other powerful interest groups. Here, the underlying point remains: such a frame of mind remains immune to any truly holistic understanding of the world and nature continues to be set up as a pure resource for human consumption. This lack of truly systemic understanding and the aggressive instrumentalism that holds sway in its stead could, as it gathers strength, hardly fail to subvert both the subtle natural interplays and delicate equilibria in which human existence is embedded and any properly receptive frame of mind that would make it sufficiently sensible of this.

It is in this sense that it is appropriate to speak of a prevailing metaphysics of mastery, for here we are installed in a highly partial reality that inherently works to exclude anything that lies beyond its purview-especially any sources of intrinsic value that transcend the human will and could prove recalcitrant to its demands. And, to return to a previously raised question: the reason that quasi-mechanical portrayals of the natural world have the ascendency is that they set the world up as something that in principle can be controlled, mastered, whereas the recognition of spontaneity and of otherness of purpose pervading the world precludes this. So installed, it becomes increasingly difficult for us properly to address the environmental issues that now face us. When nature is perceived as purely a resource, any adverse consequences of exploiting it appear simply as needing to be fixed by either current or future technologies. Essentially, any problems are taken to lie not within the human will but within those aspects of nature that prove to be resistant to it. With this in play, the central and deep issue of the adequacy of our current modalities of perception is occluded.

\section{The Philosophy of Education in the Light of Nature as the Self-Arising}

The argument that human consciousness is ineluctably environmental and involved in sustainability, and subsequent discussion of the character of nature and its significance for understanding what lies at the core of authentic human being, have implications for the content and character of education at a number of levels.

In very general terms, previous argument can be read as putting on the table the proposition that centrally education should be concerned with inviting pupils to participate in a particular frame of mind-or perhaps, better, way of being - that is energized by loving allowance rather than unbridled calculative imposition. Given that such an attitude is as much absorbed from the surrounding culture of the school as from what is formally taught, this suggests a curriculum that itself is infused with such loving allowance both in terms of its approach to pupils as individuals and in its understanding of curriculum content as what presents itself as calling for attention in the course of their ongoing engagement with their environment. In addition to helping to refine and deepen such attentiveness through providing opportunities to dwell with things in their arising and to reflect on their significances, presumably the curriculum would need to alert pupils to the myriad ways in which the metaphysics of mastery holds sway in their perceptions and to encourage experiences and reflections in which this can be disturbed and challenged. This conception of education opens a number of lines of thought for the philosophy of education. 
For example, it suggests a different perspective on some of the key concepts that traditionally have been taken to be central to the idea of education. Ideas of truth and knowledge appear that challenge some current mainstream conceptions and that invite further investigation of their educational implications. ${ }^{32}$ If primordially knowledge arises from receptivity to the non-human rather than by a process of anthropocentric construction, if the apprehension of intrinsic values is implicit in the occurring of truth, then the character of what counts as an educational situation-and underpinning notions of human wellbeing, flourishing and the good life-come up for review. With regard to the character of education, ideas of the curriculum as some kind of pre-specified programme of knowledge and skills acquisition, and the teacher-pupil relationship as orientated around the idea of transmission of this prescribed content from teacher to pupil, are severely challenged. Detailed pre-specification (on the back of which often follows managerialism and modularisation) is the bane of genuine engagement with one's environment, which (it has been argued) fundamentally is apprehended through the fluid sensing of an affective embodied self. This self is sensuous, physically as well as intellectually active and engaging. It requires freedom to respond to the spontaneous prompts and invitations experienced in unfettered participation. On this characterization, the scientism implicit in much of school culture can have deleterious effects on the ability of pupils to inhere authentically in the space that formal schooling provides.

Here, the fundamental issue is raised of the effects on their subjectivity of the environment in which pupils are required to participate. If consciousness is ineluctably environmental and places lay claim to an individual in the senses described earlier in this paper, the potential for a debilitating personal disengagement arises in situations where prespecification of learning and acceptable responses is high. If the refutation of pupils' anticipations by the school is extensive or radical, the natural flow of their intentionality becomes stymied. The pupil can feel 'out of place' and paralyzed. ${ }^{33}$ Such alienation from their immediate environment, combined with restriction of free exploration previously alluded to, threatens a kind of autism that represents the antithesis of what environmental education must achieve. This suggests a need for careful consideration in holistic terms of the milieu of anticipations that schools support and when disruption of those of incomers is edifying and when pathological.

In the context of admitting self-arising nature to the enterprise of education this matter of the character of the educational environment warrants consideration of a number of associated issues:

1. The nature and educational potential of a curriculum that emerges in response to the experiences, issues and opportunities that occur when free engagement with a naturerich environment is valued;

2. How ideas of moral education and justice that inform the school environment become modified when anthropocentric hubris is suspended and the normativity and intrinsic value of non-human nature are allowed a voice. This raises the further issue of how to conceive of our responsibilities towards nature-and the future; ${ }^{34}$

3. If authentic human being is radically ecstatic and environmental in the ways previously indicated the importance of considering schools as places-their

\footnotetext{
32 Bonnett (2015b).

33 Bonnett (2009b).

34 See, for example, Postma and Smeyers (2012), and Kemp (2015), on these matters.
} 
experienced character, culture, ethos, architecture and location-becomes an important topic for investigation; ${ }^{35}$

4. Insofar as computerization and the a growing preoccupation with electronic connectivity can be argued to be antipathetic to the ways of relating to the world valorised by knowing nature - for example, through their limitation of multisensory engagement with spontaneity in the immediate environment, and their bodied passivity - the ontology of computerized learning becomes an important area of investigation. ${ }^{36}$

Points such as these illustrate a need for a re-appraisal of the topics that should lie at the heart of philosophy of education. And returning to the large topic of the ascendance of the metaphysics of mastery and the normalisation of scientism in education, a number of further questions arise with regard to the content of the curriculum: What motives and attitudes towards nature are implicit in different areas of the school curriculum? This question is of particular importance when it is recalled that many traditional school subjects were formed historically at a time when the metaphysics of mastery was on the rise and motives of conquering and exploiting nature were pervasive. ${ }^{37}$ More broadly, if our ideas and experience of nature are central to human being in the ways previously claimed, then questions of the following kind become highly germane ${ }^{38}$ : What is nature and what is our place in it? How can we know nature and what should be our attitude towards it? Against what criteria should humankind judge its progress/success/flourishing in relation to the natural world? Ultimately: What would count as a right relationship with nature? Such questions are germane to education because they represent important, but now largely overlooked, ways of articulating our understanding of the human situation-which itself lies (or should lie) at the heart of educational thought.

Arising from discussion of these questions will be the need to analyse and investigate, along with the phenomenon of scientism and its influence in education, the nature of our inherence in the (natural) world-including those perspectives that are inclined to sustain it and those that are inclined to undermine it. For example, an examination of the arguably aggressive utilitarian-rational precepts of modernist humanism (including the ways in which they are carried forward in language through root metaphors and particular locutions $^{39}$ ) and a consideration of the possibilities of post-humanism, become important. Similarly, the character and worth of alternative views of education such as that of indigenous peoples that has arisen in reciprocity with the natural world, and the sensitivities expressed in some Romantic literature such as that of John Clare, Gerard ManleyHopkins, and William Wordsworth, call for serious study.

Taken as a whole the position outlined in this paper intimates an approach to thinking about education that valorizes receptivity, concreteness and particularity over the abstract and the analytic; holism and the ontological over the atomistic and the epistemological; 'cosmo-centrism' over anthropocentrism and cosmopolitanism; sensitivity to immanent organic elemental powers directly experienced as against abstract formulations. These, in turn, install at the heart of the educational enterprise knowledge by intimate acquaintance rather than knowledge by abstract calculation. Clearly, this latter places discussion of the

\footnotetext{
35 See, for example, Blenkinsop (2012).

36 For example, Payne (2006).

37 For a discussion of science that relates to this see Joldersma (2009).

38 Bonnett (2007).

39 Bowers (2012).
} 
nature and place of affectivity and of bodied knowledge firmly on the agenda of philosophy of education.

This returns us to the important theme of education occurring through a constantly emergent rather than pre-specified curriculum. What comes into view here is the aspiration to develop a systemic wisdom of the human situation that is rooted in learners' life-worlds enriched through direct acquaintanceship with nature. While this does not deny that it can be helpful to maintain some sort of systematic introduction to what may be identified as a range of key perspectives, and to have at hand ideas and information that can be drawn upon to elucidate them as evolving educational situations make them relevant, potentially there arise important questions concerning how generally knowledge needs to be organized in educational contexts.

For example: To what extent should knowledge be configured so as to be stored and accessed through narratives that root it in lived experience as against through abstract systematic disciplines? (And in the case of the former, which or whose narratives should be privileged?) What are the implications for practice if knowledge is presented as not exclusively the product of human agency and ingenuity, but in part, at least, as receptiveness to what is offered by other forms of agency involved in the occurring of things? How are these alternative forms of agency best understood and woven into accounts of education? And how should this affect the educational status (and perhaps character) of different modes of thought such as the scientific and the poetic? Given the character of nature as the self-arising and the varying circumstances in which education takes place, the question is also raised concerning what considerations are relevant to seeking the enrichment of the life-worlds of learners through personal encounters with the nature? This issue becomes particularly acute for education in urban contexts where the presence of self-arising nature can be less immediately apparent and some of its fundamental rhythms can be attenuated by, for example, extensive light and sound pollution.

Finally, we are brought up against the basic question of the extent to which the aim of introducing pupils to what has been referred to as a civilised inheritance of enduring traditions of thought ${ }^{40}$ - and that may lie beyond the compass of their current life-world preoccupations-is legitimate. If it is, how is it to be reconciled with the idea of a radically emergent curriculum?

To propose such questions, and to seek to reveal the complex synergies and tensions between the ideas involved, is to propose an agenda that could substantially transform the posture of philosophy of education as, largely, it currently stands.

Open Access This article is distributed under the terms of the Creative Commons Attribution 4.0 International License (http://creativecommons.org/licenses/by/4.0/), which permits unrestricted use, distribution, and reproduction in any medium, provided you give appropriate credit to the original author(s) and the source, provide a link to the Creative Commons license, and indicate if changes were made.

\section{References}

Bateson, Gregory. 2000. Steps to an ecology of mind Chicago. Chicago, IL: University of Chicago Press. Biesta, Gert. 2006. Beyond learning. Boulder, CO: Paradigm Publishers.

Blenkinsop, Sean. 2012. Four slogans for cultural change: An evolving place-based, imaginative and ecological learning experience. Journal of Moral Education 41(3): 353-368.

Bonnett, Michael. 1978. Authenticity and education. Journal of Philosophy of Education 12: 51-61.

40 Oakeshott (1972). 
Bonnett, Michael. 2004. Retrieving Nature: Education for a Post-Humanist Age. Oxford: Blackwell.

Bonnett, Michael. 2007. Environmental education and the issue of nature. Journal of Curriculum Studies 39(6): 707-721.

Bonnett, Michael. 2009a. Education and selfhood: A phenomenological investigation. Journal of Philosophy of Education: What do Philosophers of Education Do? 43(3): 357-370.

Bonnett, Michael. 2009b. Schools as places of unselving: an educational pathology? In Exploring education through phenomenology. Diverse approaches, ed. G. Dall'Alba. Oxford: Wiley-Blackwell.

Bonnett, Michael. 2012. Environmental concern, moral education, and our place in nature. Journal of Moral Education Special Issue: Moral Education and Environmental Concern 41(3): 285-300.

Bonnett, Michael. 2013. Normalising catastrophe: Sustainability and scientism. Environmental Education Research 19(2): 187-197.

Bonnett, Michael. 2015a. The powers that be: Environmental education and the transcendent. Policy Futures in Education 13(1): 42-56.

Bonnett, Michael. 2015b. Transcendent nature and the character of truth and knowledge in education. In Nature in education, ed. P. Kemp, and S. Frolund, 50-65. Zurich: LIT Verlag.

Bowers, Chet A. 2012. Questioning the idea of the individual as an autonomous moral agent. Journal of Moral Education 41(3): 301-310.

Brentano, Franz. 1995. Psychology from an empirical standpoint. London: Routledge.

Butler, Judith. 1997. Excitable speech. A politics of the performative. New York, NY: Routledge.

Carson, Rachel. 1962. Silent spring. Boston, MA: Houghton Mifflin.

Garrard, Greg. 1998. The romantic's view of nature. In Spirit of the environment, ed. David Cooper, and Joy Palmer, 113-130. New York, NY: Routledge.

Haraway, Donna. 1991. Simians, cyborgs, and women. The reinvention of nature. London: Free Association Books.

Heidegger, Martin. 1972. Being and time. Oxford: Blackwell.

Heidegger, Martin. 1977. The question concerning technology and other essays. New York, NY: Harper \& Row.

Husserl, Edmund. 2001. Logical investigations, vol. II. London: Routledge.

Joldersma, Clarence W. 2009. How can science help us care for nature? Hermeneutics, fragility, and responsibility for the earth. Educational Theory 59(4): 465-483.

Kemp, Peter. 2015. The animal: My partner. In Nature in education, ed. Peter Kemp, and Sune Frolund, 215-226. Zurich: LIT Verlag.

Oakeshott, Michael. 1972. Education: The engagement and its frustration. In Education and the development of reason, ed. R.F. Dearden, Paul H. Hirst, and R.S. Peters, 19-49. London: Routledge, Kegan \& Paul.

Payne, Phillip. 2006. The technics of environmental education. Environmental Education Research 12(3-4): 487-502.

Plumwood, Val. 1995. Nature, self, and gender: Feminism, environmental philosophy and the critique of rationalism. In Environmental ethics, ed. Robert Elliot, 155-164. Oxford: Oxford University Press.

Postma, Dirk W., and Paul Smeyers. 2012. Like a swallow, moving forward in circles: on the future dimension of environmental care and education. Journal of Moral Education 41(3): 399-412.

Rolston III, Holmes. 1999. Ethics on the home planet. In An invitation to environmental philosophy, ed. Anthony Weston. Oxford, UK: Oxford University Press.

Russell, Bertrand. 1959. The problems of philosophy. Oxford: Oxford University Press.

Seigel, Jerrold. 2005. The idea of the self. Cambridge: Cambridge University Press.

Skulason, Pall. 2015. The Wildness of Nature. Its significance for our understanding of the world. In Nature in education, ed. Peter Kemp, and Sune Frolund. Zurich: LIT Verlag.

Solomon, Robert C. 1980. History and human nature. Brighton: Harvester Press. 